\title{
Influence of Natural Volcanic Ash on Shrinkage and Cracking of Concrete
}

\author{
Jiliang Wang ${ }^{1,}$, *, Yongyan Yu ${ }^{1, b}$ \\ ${ }^{1}$ Research Institute of Highway Ministry of Transport, Beijing 100088, China \\ a178089788@qq.com, ${ }^{b} 535165839 @ q q . c o m$
}

Keywords: natural volcanic ash; workability; strength; cracking; shrinkage

\begin{abstract}
Usage of natural volcanic ash as an active mineral admixture in concrete can compensate for the shortage of traditional volcanic materials. Natural volcanic ash has significant effects on concrete workability, strength, cracking and shrinkage. The results show that natural volcanic ash in concrete has potential of developing strength in the later stage. With the fineness of ash, the strength of concrete increased in the later period. Natural ash can improve workability of concrete, but the effect is between fly ash and granulated blast furnace slag. Natural volcanic ash can delay the appearance of cracks significantly, but it increases the average crack area and the total crack area per unit area. With the increase of the fineness of natural volcanic ash, shrinkage rate increases gradually, and the shrinkage rate was slightly larger than that of fly ash concrete.
\end{abstract}

\section{Introduction}

With the infrastructure construction and the cement concrete technology, the application technology of activated mineral admixtures, such as slag powder, fly ash, zeolite and microsilicon powder, has matured. And there is a shortage of mineral admixtures. They could improve fluidity, strength and durability. And they can also reduce the amount of cement, the cost and protect the environment. So economic and social value is shown, when mineral admixtures are used in cement. In some areas, due to historical reasons, the industrial is underdevelopment, or the construction of infrastructure is too fast, artificial ash materials such as fly ash are scarce. And the typical volcanic mineral micropowder resources, which are made of the volcanic rock, such as basalt, tuff, pyroclastic rock, zeolite, Pumice rock, diatomite, etc, are abundant. Compared with the former, the research and application of typical volcanic ash mineral powder are lagging, and lack corresponding norms and technical standards. In order to make up for the shortage of traditional volcanic materials, it is inevitable to choose natural volcanic ash as the active mineral admixture of concrete.

As an important auxiliary cementitious material, ash material has a long history of application. The active $\mathrm{SiO}_{2}$ and $\mathrm{Al}_{2} \mathrm{O}_{3}$ in the natural volcanic ash material can gradually produce calcium silicate and calcium aluminate with $\mathrm{Ca}(\mathrm{OH})_{2}$ in cement, which are called volcanic ash reactions. Reaction can improve the quality and quantity of hydrates in cement concrete, so that the strength and other performance indexes of cement can be greatly improved. However, there are some problems in the application of natural volcanic materials. The basic properties of natural volcanic materials vary greatly from formation ages, conditions and environment. And most natural volcanic 
materials have high alkali content, which will bring negative effects on concrete. In this paper, the effect of Yunnan fine natural ash material on the shrinkage and crack resistance of cement concrete is studied. The study provides a reference for large-scale application of natural volcanic material.

\section{Raw Materials and Methods}

\subsection{Raw Materials}

(1) Cement

P.O42.5 cement, made by the Jinyu cement plant in Beijing, was used in the experiments. The physical performance of the cement is shown in Table 1.

Table 1 Physical performance of the cements

\begin{tabular}{|c|c|c|c|c|c|c|c|c|c|}
\hline & \multirow{2}{*}{$\begin{array}{c}\text { surface area } \\
\mathrm{m}^{2} / \mathrm{kg}\end{array}$} & \multirow{2}{*}{$\begin{array}{c}\text { Standard } \\
\text { consistency } \\
\%\end{array}$} & \multirow{2}{*}{ soundness } & \multicolumn{2}{|c|}{ setting time (min) } & \multicolumn{2}{|c|}{$\begin{array}{l}\text { Flexural strength } \\
\qquad(\mathrm{MPa})\end{array}$} & \multicolumn{2}{|c|}{$\begin{array}{c}\text { Compressive } \\
\text { strength (MPa) }\end{array}$} \\
\hline & & & & $\begin{array}{l}\text { Initial } \\
\text { time }\end{array}$ & $\begin{array}{l}\text { Final } \\
\text { time }\end{array}$ & 3d & $28 d$ & 3d & $28 d$ \\
\hline Cement & 347 & 27.4 & Pass & 211 & 285 & 6.3 & 8.7 & 31.1 & 51.2 \\
\hline
\end{tabular}

(2) Aggregate

The fine aggregate is river sand, produced in Qinhuangdao, Hebei Province. The fine modulus of sand is 2.67, with $0.8 \%$ mud content. The grading curve is shown in Figure 1, which conforms to the requirements of District II matching in the national standard Sand for Construction (GB/T 14684-2001). The coarse aggregate is taken from Beijing. It is $4.75 \sim 26.5 \mathrm{~mm}$ continuous grade limestone gravel, its grading curve is shown in Figure 2.

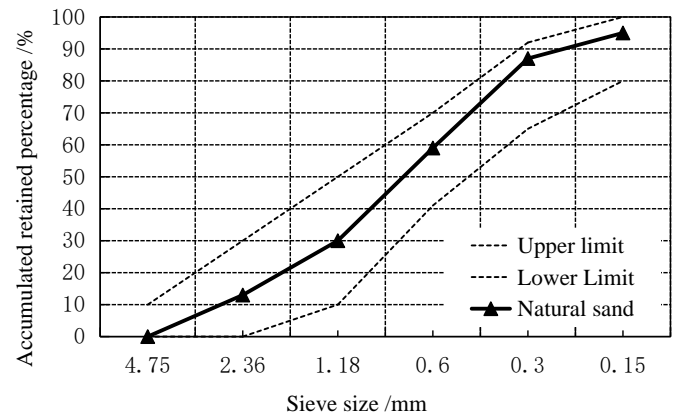

Fig. 1 Grading curves of natural sand

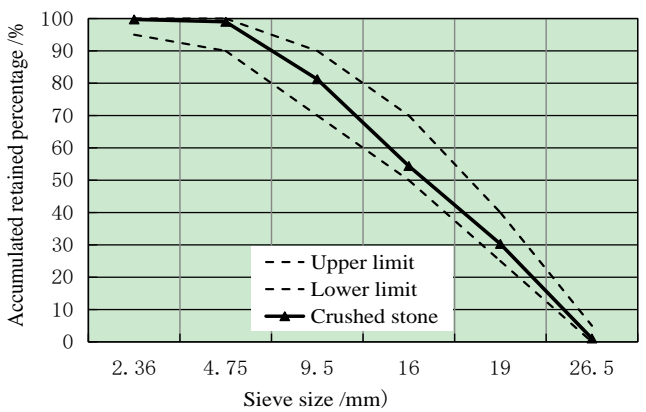

Fig. 2 Grading curves of crushed sand 


\section{(3) Additives}

Polycarboxylic acid was used as the effective water reducing agent, the solid content was $20 \%$, the water reducing rate was $26 \%$ and the gas content was $2.5 \%$.

(4) Volcanic ash and mineral mixtures

The fly ash is the first grade fly ash produced in Hebei province, with 93\% water requirements. Type S95 slag from Beijing, with a specific surface area of $453 \mathrm{~m}^{2} / \mathrm{kg}$. Volcanic ash is produced from HH and JT ash in Yunnan province. Ash source JT-1, JT-2, JT-3 from same origin, but with different grinding fineness.

\subsection{Methods}

(1)Concrete workability test was tested according to "Standard for test method of performance on ordinary fresh concrete” (GB/T50080). Compressive strength and flexural strength were tested according to "Experimental Methods and Standards of Mechanical Performance to Ordinary Concrete"(GB/T50081). The dimension of the cubic specimens for testing compressive strength is $150 \mathrm{~mm} \times 150 \mathrm{~mm} \times 150 \mathrm{~mm}$, and prism specimens of $150 \mathrm{~mm} \times 150 \mathrm{~mm} \times 550 \mathrm{~mm}$ are for the flexural strength testing.

(2) Plastic cracking test adopted the plate method invented by professor Y. kasai. The apparatus used for the evaluation of plastic cracking is shown in Fig.3. The device is a steel form of $600 \mathrm{~mm} \times 600 \mathrm{~mm} \times 63 \mathrm{~mm}$ with 14 bolts of $\Phi 10 \times 100 \mathrm{~mm}$ mounted regularly at each four sides of the rigid frame. In order to avoid frictions between concrete and bottom plate of the restriction steel form, a Teflon sheet was placed at the bottom of the form. Concrete was placed in the restriction steel form and cured with a cover of plastic film for 2 hours under a constant temperature of $30^{\circ} \mathrm{C}$ and relative humidity of $60 \%$. Subsequently, it was exposed to an air flow with a velocity of $8 \mathrm{~m} / \mathrm{s}$ under a constant temperature of $30^{\circ} \mathrm{Cand}$ relative humidity of $60 \%$. Then the number of cracks, crack length and crack width were measured until the age of 24 hours.

A quantitative analysis was made as follows:

(1) Average crack area

$$
a=\frac{1}{2 N} \sum_{i}^{N} W_{i} \cdot L_{i} \quad\left(\mathrm{~mm}^{2}\right)
$$

(2) Number of cracks per unit area

$$
b=\mathrm{N} / \mathrm{A} \quad\left(\text { number } / \mathrm{m}^{2}\right)
$$

(3) Total crack area per unit area

$$
c=a \cdot b \quad\left(\mathrm{~mm} / \mathrm{m}^{2}\right)
$$

Criteria: 1) only very fine cracks, 2) average crack area is less than $10 \mathrm{~mm} 2,3$ ) the number of crack per unit area is less than $10 / \mathrm{m}^{2}$, and 4) the total crack area per unit area is less than 100 $\mathrm{mm}^{2} / \mathrm{m}^{2}$. According to the four criterions above, the resistance to plastic cracking was divide into five grade: I satisfy all four conditions, II satisfy three of four, III satisfy two of four, IV satisfy one of four and $\mathrm{V}$ satisfy nothing.

(3) Dry shrinkage is tested according to "Standard for test methods of long-term performance and durability of ordinary concrete"(GBJ50082). The dimensions of specimens for testing dry shrinkage are $100 \mathrm{~mm} \times 100 \mathrm{~mm} \times 515 \mathrm{~mm}$, both whose ends lay metallic gauge head, and testing machine adopts bow-spiral micrometer. The base length of specimen is tested after curing $1 \mathrm{~d}$ in standard curing room. The dry age of the specimen is calculated after measuring the base length. 


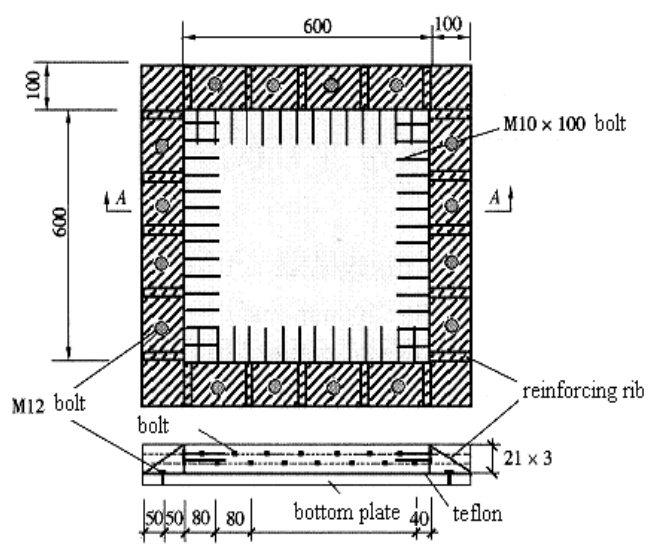

Figure 3 Flat Test Mold

\section{Experimental Results and Analysis}

In order to analyze the effect of natural volcanic ash material on the crack resistance of concrete, C40 concrete was used in the research, and mineral admixtures were used instead of cement. The total amount of cementitious material is $450 \mathrm{~kg} / \mathrm{m}^{3}$, the substitution rate of mineral admixtures is $30 \%$ and the ratio of hydroglue to 0.35 .

\subsection{Influence of natural volcanic materials on workability}

The properties of the new concrete include initial slump/slump flow, time loss for slump/slump flow. The test method is based on "Test Method of General Concrete Mix Properties" (GB/T50080).

The effects of admixtures on the workability of newly mixed concrete are shown in Table 2 . The results show that the initial slump and the slump flow of the concrete mixture are not different from those of $30 \%$ fly ash, mineral powder and JT. When fly ash is used as admixture, the slump flow of fresh concrete is the largest, reaching $520 \mathrm{~mm}$, and the demand of water reducing agent is the least. When pure cement concrete as cementitious material is used in concrete, the initial slump and slump flow are small, and there is a slight bleeding phenomenon. The initial slump of $\mathrm{HH}$ natural ash and JT ash as admixtures reached $200 \pm 10 \mathrm{~mm}$, the water-reducing agent need $1.6 \%$. And the concrete workability is poor, when water-reducing agent is1.2 \%, in $\mathrm{HH}$ natural ash and JT ash concrete.

Table 2 Properties of natural volcanic material

\begin{tabular}{|c|c|c|c|c|c|c|c|}
\hline item & $\begin{array}{c}\text { Fineness( } \\
\%)\end{array}$ & $\begin{array}{c}\text { Epidermal } \\
\text { density } \\
\left(\mathrm{g} / \mathrm{cm}^{3}\right)\end{array}$ & $\begin{array}{c}\text { surface area } \\
\left(\mathrm{m}^{2} / \mathrm{kg}\right)\end{array}$ & $\begin{array}{c}\text { Water } \\
\text { requirements( } \\
\%)\end{array}$ & $\begin{array}{c}\text { Alkali } \\
\text { content( } \\
\%)\end{array}$ & $\begin{array}{c}\text { Water } \\
\text { content( } \\
\%)\end{array}$ & $\begin{array}{c}\text { Active } \\
\text { Index(\%)28d }\end{array}$ \\
\hline HH & 15.8 & 3.08 & 431 & 102 & 5.55 & 0.2 & 71.3 \\
\hline JT-1 & 19 & 2.74 & 305 & 93.6 & 4.84 & 0.1 & 73.6 \\
\hline JT-2 & 10 & 2.76 & 423 & 94.4 & 4.84 & 0.2 & 73.6 \\
\hline JT-3 & 6 & 2.76 & 486 & 95 & 4.84 & 0.2 & 73.6 \\
\hline slag & 8.2 & 2.81 & 453 & 101 & 0.38 & 0.3 & 101 \\
\hline fly ash & 9.0 & 2.23 & 447 & 93 & 1.37 & 0.1 & 85.0 \\
\hline
\end{tabular}

The effect of natural ash fineness on the workability of fresh concrete is shown in Table 2. According to the results of table 2, with the increase of grinding time, fineness and specific surface area increase. And the workability of natural volcanic ash as admixture improves obviously. The 
slump is $220 \mathrm{~mm}$, and slump flow is $530 \mathrm{~mm}$, when surface area is $486 \mathrm{~m}^{2} / \mathrm{kg}$.

It is shown from the above study that JT natural volcanic ash as admixtures has little difference from fly ash as admixtures when the amount of admixtures is not much different. As can be seen from Table 2, the initial slump of fly ash concrete and JT series of natural ash concrete is $200 \pm$ $10 \mathrm{~mm}$, the initial slump flow is $450-550 \mathrm{~mm}$. The loss of slump and slump flow in $1 \mathrm{~h}$ is small. The slump, slump flow and loss satisfied with workability on construction. It can be seen that natural volcanic ash as concrete admixture can meet the engineering construction requirements. And workability of natural volcanic concrete and of fly ash concrete is similar.

\subsection{Influence of natural volcanic materials on compressive strength}

The physical and mechanical properties of different types of admixtures and natural volcanic ash were studied systematically.

The effect of admixtures on compressive strength is shown in Table 3 . The results of table 3 show that the N3 groups with $30 \%$ ore powder have the greatest strength at three ages, which shows that the ore powder has a good effect on concrete strength. Excluding the N3 group, compressive strength of pure cement is the greatest. That means fly ash and natural ash reduced the strength of the concrete. At the 56d age, compressive strength of pure cement is higher than that of JT 3.5\%. The difference is not obvious. At three ages, compressive strength of fly ash and JT is similar. In 56d, strength of JT is higher than that of fly ash $4.3 \%$. Strength of HH is the lowest, when compared with fly ash and JT. It is indicates that HH has lower activity than fly ash and JT volcanic ash.

Table 3 Effect of admixtures on workability in Concrete

\begin{tabular}{|c|c|c|c|c|c|}
\hline \multirow{2}{*}{ Number } & \multirow{2}{*}{ admixture } & \multirow{2}{*}{$\begin{array}{c}\text { water reducing } \\
\text { agent dosage } \\
(\%)\end{array}$} & \multicolumn{2}{|c|}{ slump / slump flow (mm) } & \multirow{2}{*}{ working performance } \\
\hline & & & Initial & $1 \mathrm{~h}$ & \\
\hline N1 & - & 1.2 & $190 / 420$ & 170 & slight bleeding \\
\hline N2 & Fly ash & 1.1 & $210 / 520$ & $205 / 510$ & good viscosity and fluidity \\
\hline N3 & slag powder & 1.2 & $200 / 490$ & $190 / 490$ & good viscosity \\
\hline N4 & $\mathrm{HH}$ & 1.6 & $195 / 460$ & 160 & $\begin{array}{c}\text { good viscosity; poor } \\
\text { fluidity }\end{array}$ \\
\hline N5 & JT-1 & 1.2 & $200 / 490$ & $190 / 480$ & slight bleeding \\
\hline N6 & JT-2 & 1.2 & $205 / 480$ & $200 / 480$ & good viscosity and fluidity \\
\hline N7 & JT-3 & 1.2 & $220 / 530$ & $220 / 520$ & good viscosity and fluidity \\
\hline
\end{tabular}

The impact of natural ash fineness on concrete compressive strength is shown in Table 3. The compressive strength of concrete increases with the increase of natural ash surface area at all ages. The results of the 3.1 show that with the higher the fineness of natural ash, the workability increase. So within reasonable energy consumption, the finer the natural ash is better.

Table 4 Effect of Combustion Type on Compressive Strength of Concrete

\begin{tabular}{|c|c|c|c|c|}
\hline \multirow{2}{*}{ Number } & \multirow{2}{*}{ admixture } & \multicolumn{3}{|c|}{ Compressive Strength (MPa) } \\
\cline { 3 - 5 } & & $7 \mathrm{~d}$ & $28 \mathrm{~d}$ & $56 \mathrm{~d}$ \\
\hline N1 & - & 43.6 & 51.6 & 62.4 \\
\hline N2 & Fly ash & 40.2 & 50.4 & 57.8 \\
\hline N3 & slag powder & 41.4 & 53.1 & 65.8 \\
\hline N4 & HH & 37.7 & 47.5 & 57.5 \\
\hline N5 & JT-1 & 35.8 & 45.0 & 57.0 \\
\hline N6 & JT-2 & 40.2 & 48.9 & 60.3 \\
\hline N7 & JT-3 & 40.9 & 48.6 & 63.0 \\
\hline
\end{tabular}




\subsection{Effect of natural volcanic ash materials on plastic cracking}

Due to the widespread use of mineral admixture and admixture, the early shrinkage of concrete increases. The deformation of concrete in the first three days(i.e. early age) is most complicated, including all plastic subsidence shrinkage, autogenetic shrinkage, chemical shrinkage of cement hydration and dry shrinkage of concrete surface water loss, which account for a large proportion of early age shrinkage. This section compares the effect of natural volcanic ash and other mineral admixtures on plastic cracking of concrete.

Table 5 shows that various mineral admixtures obviously affect the time of plastic cracks in concrete, and different kinds of mineral admixtures affect the time of plastic cracks differently. When fly ash is used as mineral admixtures, the time of the first plastic crack in concrete is delayed. The phenomenon may due to morphological of fly ash, which ensures that there is more free water in concrete, which can move to the concrete surface quickly, and delay the time of the occurrence of plastic crack. However, because the fineness of ore powder is higher than that of fly ash, and the water retention is better. So the appearance of plastic crack is earlier than that of adding fly ash concrete. The results of Table 5 show that the addition of ore powder is not conducive to the control of plastic cracks. Similarly, the appearance of plastic crack was delayed by the addition of two new types of ash to the concrete. That means the first plastic crack was delayed by the ash. It can be seen from the JT ash, the time of the first plastic crack was reduced with the increase in the fineness of the ash. So the increase of fineness of ash is detrimental to cracks. However, compared with pure cement, natural volcanic relief the appearance time of cracks.

It can be seen from the results of table 5 that the average crack area and total crack area of concrete increased significantly after the equal substitution of cement by mineral admixtures such as fly ash, mineral powder and ash. And cracking resistance grade decreased. This is mainly because with the increase of the active mineral admixtures, the hydrated products in concrete decrease gradually, and resistance to shrinkage decreases, which makes the plastic cracking more obvious. At the same time, it can be seen from the results that with the increase of the fineness of the natural volcanic powder, the average crack area and the total crack area increased significantly, that means, the fineness of natural volcanic material should not be increased immoderate. Early maintenance of the concrete should be strengthened, when the smaller volcanic ash is used, to reduce the probability of plastic cracks in the concrete.

Table 5 Effect of mineral admixtures on the time of first plastic crack in concrete

\begin{tabular}{|c|c|c|c|c|c|c|c|}
\hline Number & N1 & N2 & N3 & N4 & N5 & N6 & N7 \\
\hline Time /min & 415 & 465 & 390 & 425 & 490 & 470 & 435 \\
\hline
\end{tabular}

Table 6 Effect of mineral admixtures on plastic cracking of concrete

\begin{tabular}{|c|c|c|c|c|c|c|c|}
\hline Number & $\begin{array}{c}\text { crack } \\
\text { area } \\
/ \mathrm{mm}^{2}\end{array}$ & $\begin{array}{c}\text { Number of } \\
\text { cracks } \\
/ \text { Numbers }\end{array}$ & $\begin{array}{c}\text { Cracks } \\
\text { Characte } \\
\text { ristics }\end{array}$ & $\begin{array}{c}\text { Average } \\
\text { crack } \\
\text { area } \\
/ \mathrm{mm}^{2}\end{array}$ & $\begin{array}{c}\text { Number of } \\
\text { cracks per unit } \\
\text { area } \\
/\left(\text { numbers } \cdot \mathrm{m}^{-2}\right)\end{array}$ & $\begin{array}{c}\text { cracked area } \\
\text { per unit area } \\
/\left(\mathrm{mm}^{2} \cdot \mathrm{m}^{-2}\right)\end{array}$ & $\begin{array}{c}\text { Cracking } \\
\text { resistance } \\
\text { grade }\end{array}$ \\
\hline N1 & 143.3 & 51 & Very thin & 2.81 & 141.7 & 398.1 & III \\
\hline N2 & 189.2 & 63 & Very thin & 3.00 & 175.0 & 525.6 & III \\
\hline N3 & 208.7 & 52 & fine & 4.01 & 144.4 & 579.7 & VI \\
\hline N4 & 312.5 & 48 & fine & 6.51 & 133.3 & 868.1 & VI \\
\hline N5 & 163.2 & 57 & Very thin & 2.86 & 158.3 & 453.3 & III \\
\hline N6 & 191.2 & 60 & Very thin & 3.19 & 166.7 & 531.1 & III \\
\hline N7 & 196.5 & 51 & Very thin & 3.85 & 141.7 & 545.8 & III \\
\hline
\end{tabular}




\subsection{Effects of natural volcanic ash materials on shrinkage}

Figure 4 shows that the early shrinkage developed rapidly, especially before 28d, and the increase of shrinkage softened with time. Shrinkages of concrete with different mineral admixture shows different trends. The shrinkage of concrete with mineral admixture is slightly increased. The shrinkage of mineral admixture concrete is similar with pure concrete. But Fly ash reduces the shrinkage rate of concrete obviously. The $\mathrm{HH}$ and JT volcanic ash could inhibit shrinkage too. Shrinkage decreased $1 \%$ and $31 \%$ in 150d in HH and JT volcanic ash concrete. Shrinkage of JT decreases significantly. While $\mathrm{HH}$ effects on the decrease of shrinkage slightly, when compared with base concrete.

The shrinkage rate of concrete with mineral admixture in the N2 $~$ N7 groups decreased significantly. The shrinkage rate of $150 \mathrm{~d}$ decreased by $10 \%$ to $20 \%$, when compared with N1. All kinds of mineral admixtures can reduce the shrinkage of concrete. Natural ash can reduce the shrinkage of concrete, but the shrinkage rate is slightly higher than that of fly ash concrete.

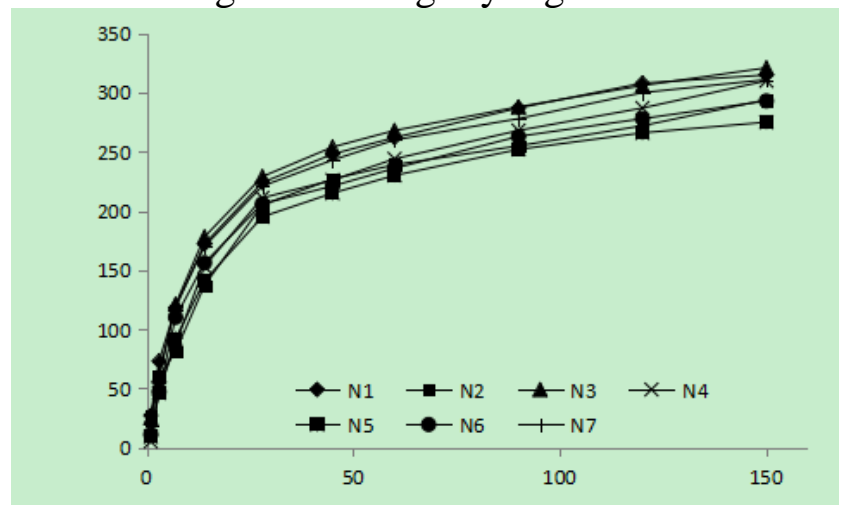

Figure 4 Variation of concrete shrinkage with age

\section{Conclusion}

(1) The chemical composition of volcanic ash is mainly $\mathrm{SiO}_{2}, \mathrm{Al}_{2} \mathrm{O}_{3}$ and $\mathrm{Fe}_{2} \mathrm{O}_{3}$, and the content of natural volcanic ash $\mathrm{K}_{2} \mathrm{O}$ and $\mathrm{Na}_{2} \mathrm{O}$ is relatively high, about $5 \%$.

(2) The activity index of volcanic ash is lower than that of mineral powder and fly ash. Natural volcanic ash as admixtures in concrete has high potential for later strength; The activity index of natural volcanic ash increases with the fineness, which contributes to strength in later.

(3) Natural volcanic ash can improve workability of concrete, but the effect is lower than fly ash, but better than granulated blast furnace slag powder.

(4) When natural volcanic ash material is used, the appearance of crack can be significantly delayed. But cracking area of natural ash concrete is similar to fly ash and ore powder concrete. The average crack area and the total crack area per unit area increased significantly, when mineral admixture is used in concrete.

(5) The shrinkage of concrete can be reduced by natural ash, but the shrinkage rate of concrete is slightly larger than that of fly ash concrete. And the shrinkage rate increased with fineness, when natural volcanic ash is used in concrete.

\section{Acknowledgments}

This work was financially supported by Fundamental Research Funds for the Central research institutes (RIOH 2015-9006) 


\section{References}

[1] Shen Yushan, Wen Xinlan, Xia Jingliang. Research on the influence of Africa pozzolan on shrinkage and crack resistance of concrete[J].Building Science, 2017(03):46-50.

[2] Ding Lujing. Research on the micro-cracks induction and self-healing mechanism by fly ash in the cement paste[D]. Wuhan University of Technology, 2014.

[3] Yang Ruimei, Wang Fulai, Gong Aimin. Application and Research of Erosion and Crack Resistant Concrete Based on Thermal Environment[J]. Water Conservancy Science and Technology and Economy, 2012(09):69-72.

[4] Yin Liying. Effect of mineral admixtures on the shrinkage of hardened cement [D]. Henan University, 2012

[5] Liu Jingwei. Research on effect of micro-nano pozzolan on early-age cracking of cement concrete. [D]. Harbin Institute of Technology, 2017. 